\title{
"AYAS": From Aerospace Club to Aerospace Society
}

\author{
Grigoryan Avetik E.* \\ "AYAS" Aerospace Society, Yerevan, Armenia
}

\begin{abstract}
The history of educational activity and linking the education with research in the aerospacerelated areas in Armenia is presented - all the way from the creation of an extra-curricular study group for school students dubbed the "AYAS" Aerospace Club to the foundation of the "AYAS" Aerospace Society.
\end{abstract}

Keywords: education, aerospace, Armenia

\section{The Very Start}

In September 1988 we created in Yerevan a new extra-curricular study group for school students who are interested in aerospace-related areas, namely aeronautics, aviation, astronomy, and astronautics. Our goal was to:

- encourage and develop school and university student's interests towards aerospace-related areas, science and technology, invention and design, provide deep knowledge and understanding of everything related to the Universe and its exploration;

- conduct events contributing to our goals (educational courses, seminars, discussions, excursions, interesting and instructive meetings with professionals from Armenia and abroad);

- develop scientific and educational research projects involving as well related specialists;

- involve also the public in our activity to try to contribute to higher understanding and valuing of science and technology in Armenia.

We called this group "AYAS" Aerospace Club keeping in mind that at some point we will be grown enough for our dream to come true and "AYAS" will stand for "Armenian Youth Aerospace Society" bringing together a lot of young people interested in STEM, space, research and investigation, discovery and innovation.

Later, we realized that we had really created something new, dissimilar to other study groups oriented towards the same areas due to our specific approach that includes three main aspects:

- strong faith in the ability of students to gain in-depth knowledge of STEM, the power of their imagination and ability to innovate;

- complete freedom for the students for creative thinking and opportunities for engaging their abilities;

- education which instead of dogmatic approach (just memorizing pure information, getting limited set of skills and narrow specialization), motivates to get real knowledge by asking questions, digging into underlying basics of any information and understanding deeply all the studied areas and the relationships between them - the basis for creative thinking.

*avgrig@ayaspace.info 
Initially, we had just a few $10^{\text {th }}$-grade school students having enough knowledge to develop a preliminary innovative concept for a space mission. The first task was to develop a design of a spacecraft that could drill the Moon deeper than ever and bring the soil samples to Earth. In result of intensive research work and brainstorming, our students decided to use the idea of Russian engineer Mikhail Tsiferov for digging into the Earth's soil more efficiently by means of the jet stream of a missile device. The tests of such a device weighing $25 \mathrm{~kg}$ performed in 1968 showed excellent results - it drilled a well with a depth of tens of meters in a soil obviously harder than the Moon's soil.

We developed a new version of that missile device modernized for the Moon, the spacecraft carrying that device (the lander and the ascent stage), and the device that could go down the well, take 30 soil samples from the layers of different levels, rise back, and put the filled sample cartridges into the return capsule. All technical solutions, material choices, sizes, masses, and layout were defined and justified by calculations. We also developed a specific technology for drilling enough deep into the wall of the well for taking soil samples chemically unaltered during the missile penetration.
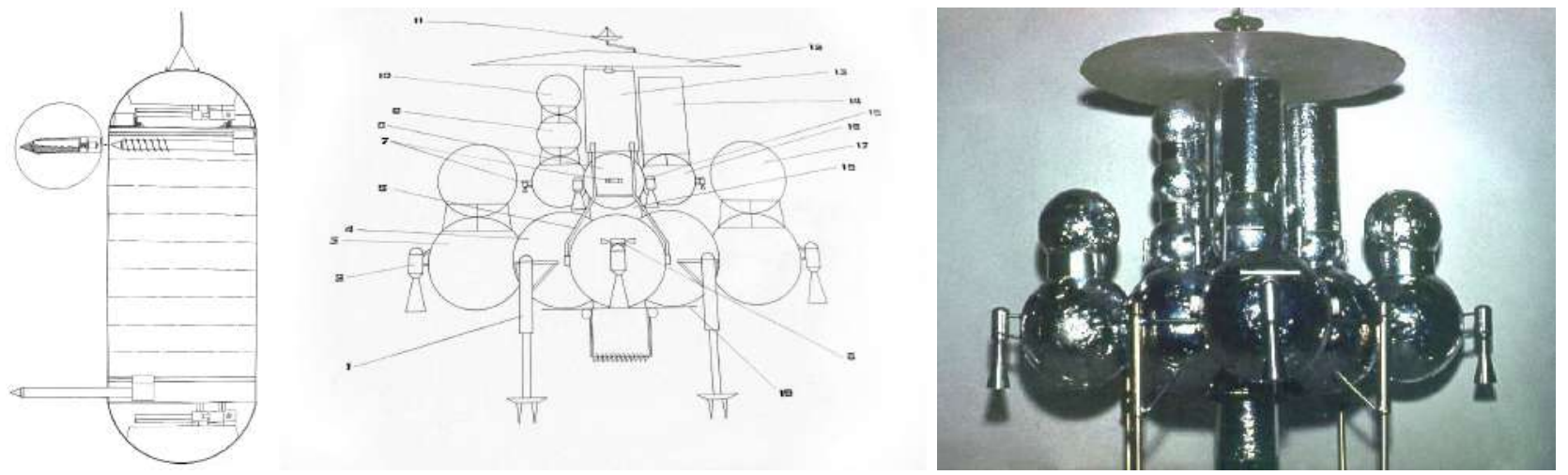

Figure 1. The "Ani" robotic space probe.

The estimated overall characteristics of the spacecraft, that we called "Ani" robotic space probe (Figure 1), proved the feasibility of this project within the scope of space technologies and transportation systems available at that time.

This was an excellent example of a design task that could stimulate interest and would require applying knowledge of mathematics, physics, chemistry, celestial mechanics, rocket science, programming, etc., thus resulting in a significant educational outcome.

We presented this project at the "Space" All-Union Contest of the USSR in 1989 and got "Yuri Gagarin" diploma from the Federation of Cosmonautics of the USSR for the best theoretical justification. The work was presented by the $10^{\text {th }}$-grade student Hayk Sargsyan. He then graduated the Yerevan State University (YSU) and quickly climbed high in his career: became an outstanding physicist, Doctor of Science, professor, member of the committees of the Republican Olympiads in physics and YSU entrance exams in physics of different years, published numerous articles in highly ranked local and international scientific journals, taught physics at Shirakatsi Seminary, Physic-mathematical school in Yerevan, Physics Department of YSU and Saint Petersburg State University, supervised numerous graduate and post-graduate works leading his students and fellows up to the degree of Doctor of Science. To this day, he is in close contact with "AYAS", participates in our events and supports us in every way.

Our next project developed in 1990 was the Lunar Observatory "Shirakatsi" (Figure 2). It was designed as a version of the Hubble Space Telescope that could be set on the Moon to operate from there benefiting from the advantageous moon conditions for astronomical observations.

The long night duration (14 days) providing the possibility of much longer exposures, Moon's slow axial rotation requiring slower rotations of the telescope's mounting for tracking the object, the firm foundation for the mounting unlike for orbital telescopes, the low night temperature decreasing the noise level and thus increasing the telescope's sensitivity, and finally the absence of atmosphere make the Moon an ideal platform for such a telescope. The only disadvantage is the big distance from Earth making the service missions very hard and expensive and requiring such a level of safety for the telescope's systems that can ensure its operation (remotely controlled from Earth) for decades. 

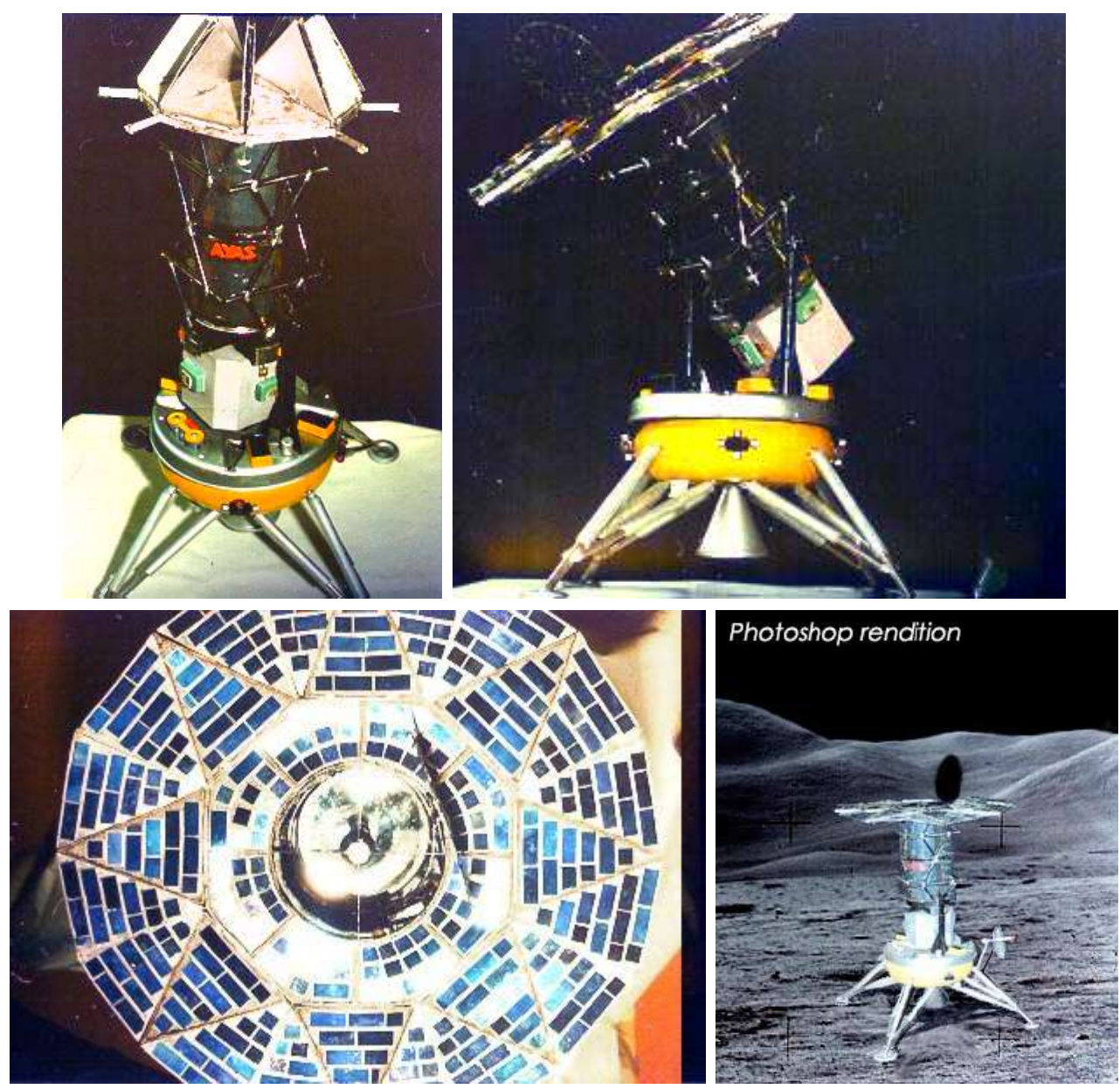

Figure 2. Lunar Observatory "Shirakatsi".

Again our design and calculations proved the feasibility of the project given the payload capabilities of the Energia booster available at that time. Our $10^{\text {th }}$-grade student Tigran Ghazaryan presented this project at the "Space" All-Union Contest of the USSR and won the first prize. The representative of the Federation of Cosmonautics of the USSR ranked it as the only really feasible project among others and worth for realization.

After this success, we proceeded with a new, more sophisticated project - the "Noah" lander for the first manned Mars mission (Figure 3). However, because of the lack of financial support, we couldn't participate in the International Student Contest "Together to Mars" that was organized by the Planetary Society and held next year in Washington. Unfortunately, a lot of innovative ideas, constructive solutions, calculations, drawings and impressive results of computer simulations of our lander's descent from areocentric orbit to the surface of Mars and ascent of its ascent stage back to the same orbit remained on the shelf.

One can imagine our reaction to the NASA's rendering of a perspective lunar rover released in 2007 (16 years later) showing a novel approach on how to prevent the lunar dust harmful for astronauts' health entering the Moon-based habitats. In our project of 1991, the same approach was proposed not only for resolving the dust challenge but also for preventing mutual biological contamination between the ecosystems of Earth and Mars. 

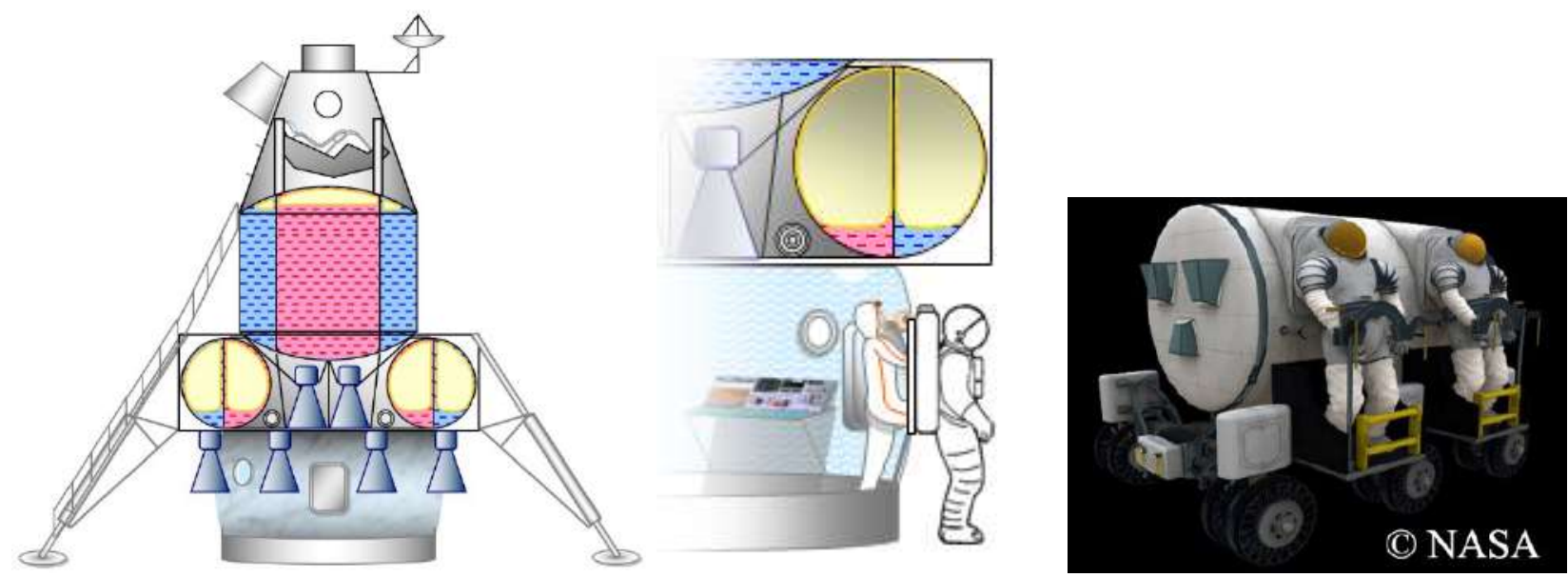

Figure 3. The "Noah" Mars Lander.

\section{Hard Times and New Beginnings}

After the collapse of the USSR, hard times came for Armenia. We could hardly continue our classes but never stopped. The development and testing of a two-year educational course were in progress. Having no heating in winter we had to assign different research topics for every student so that they could do their work at home under the remote supervision of the mentor and then bring a written report and present the results of their research works to the group in spring. The procedure of reporting was similar to defending a bachelor thesis. All this was useful for them also for getting acquainted with the traditional ways of conducting scientific research work and presenting the results.

Such presentations soon became traditional, and when the University students (mainly "AYAS" graduates) started participating in this work, we reached another major milestone (Figure 4). In October 1995 we held a youth symposium, where both invited specialists from various scientific institutions and "AYAS" members presented the results of their research works.
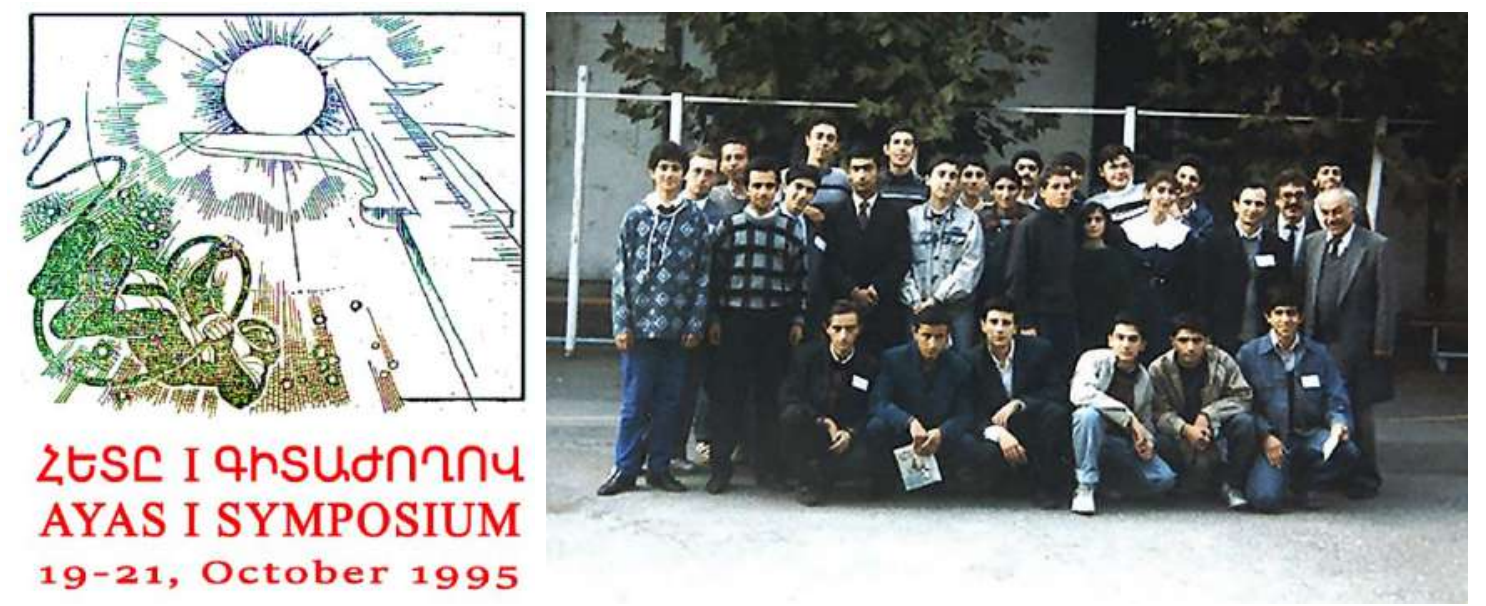

Figure 4. Participants of the "AYAS" $1^{\text {st }}$ Symposium.

Later, some of those students presented these works at the Physics Department of YSU as their diploma studies. This three-day symposium, organized in accordance with the traditional procedures of international symposiums, was an unprecedented event in the history of Armenia.

In August of the same year "AYAS" actively participated in arranging and holding the Republican Astronomy Olympiad and Astronomical School (Figure 5), organized by the Byurakan Observatory. About $30 \%$ of the participants were "AYAS" members. Our school students were awarded $1^{\text {st }}$ and $2^{\text {nd }}$ diplomas and the university students presented their research works. 


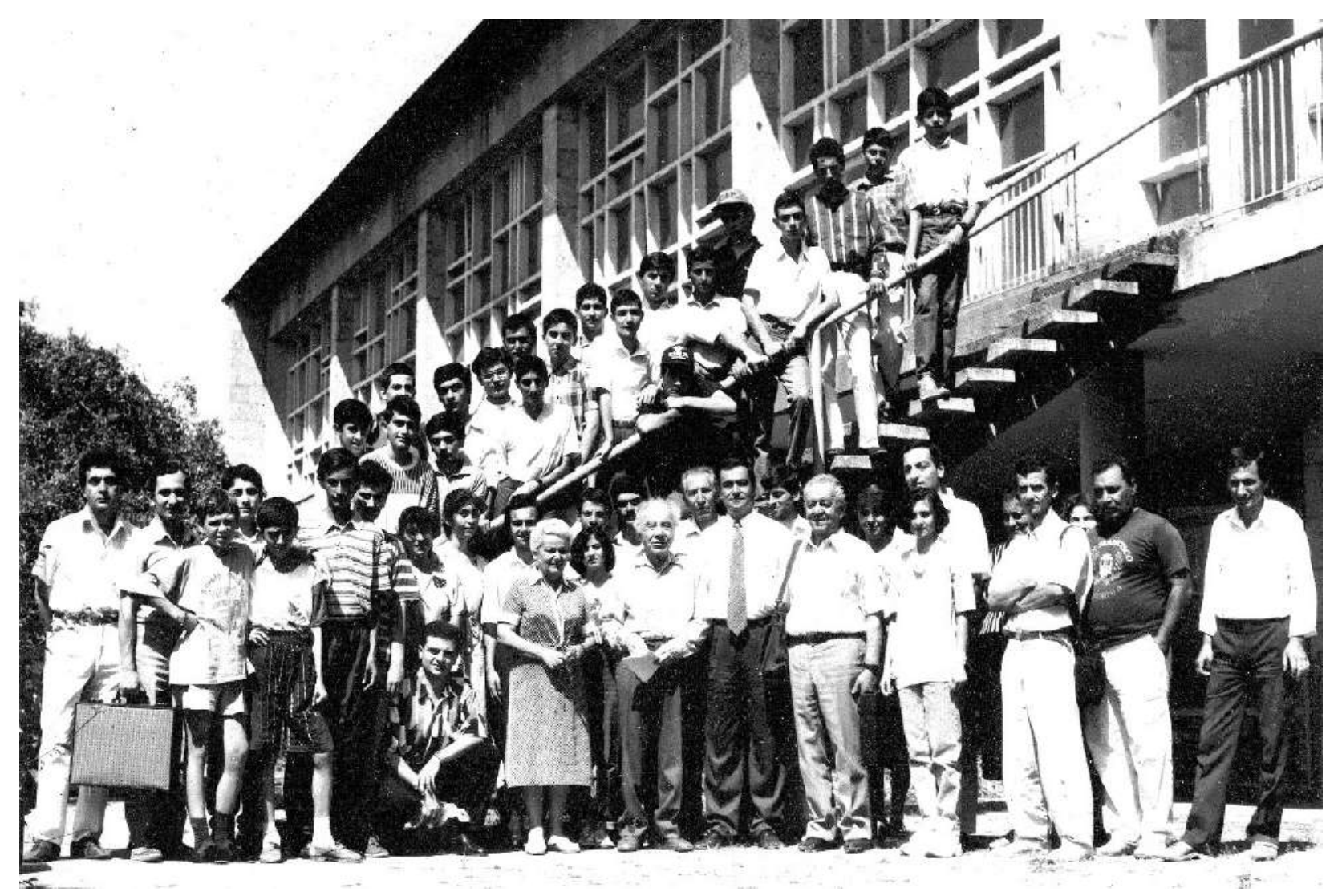

Figure 5. Republican Astronomy Olympiad and Astronomical School in Byurakan, 1995.

\section{Model Rocketry}

In the following years we intensified the search for new solutions in rocket modeling (Figure 6). We were developing new automated systems and conducting flight tests at Arzni airport. Model rocketry became a very useful and creative component of our activity.
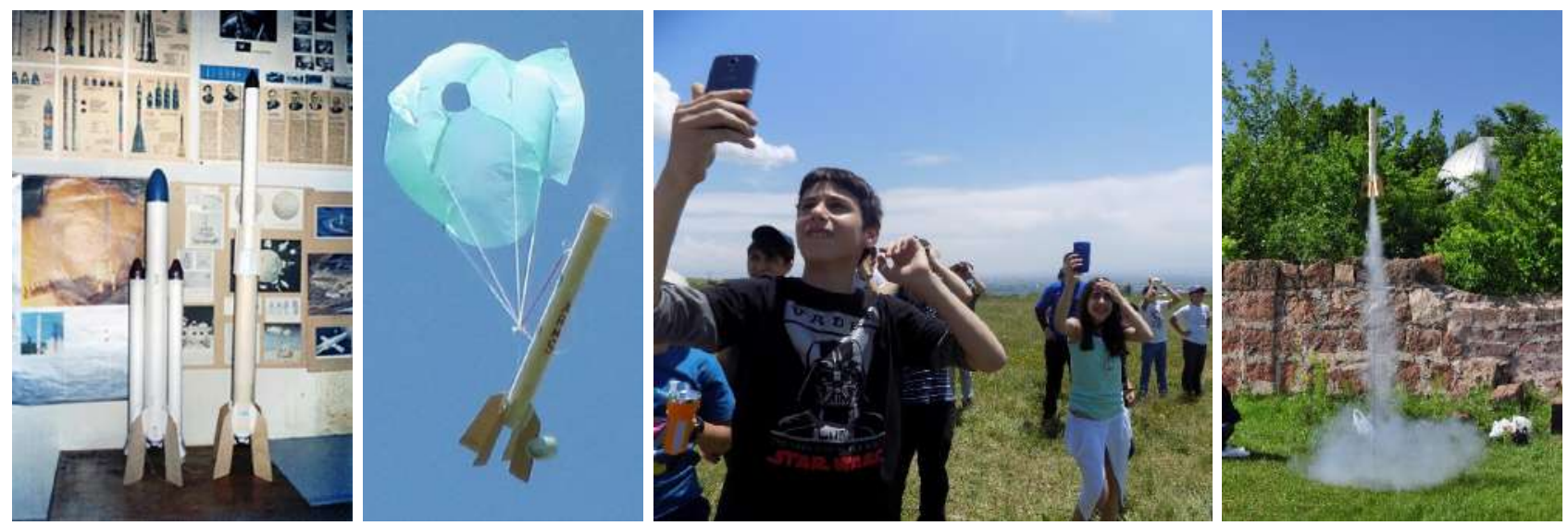

Figure 6. Model rocketry.

Once again we posed a difficult task for us - to create models of air-to-ground missiles. To achieve this goal, we developed a special ignitor for the rapid and reliable ignition of the rocket engine, rail launchers to be attached under the wings of a remote controlled model aircraft and even small warhead equipped with a shock fuse. Since 1996, this system has shown high reliability and a spectacular flight of the rocket during all tests (Figure 7). This was also an unprecedented success. 

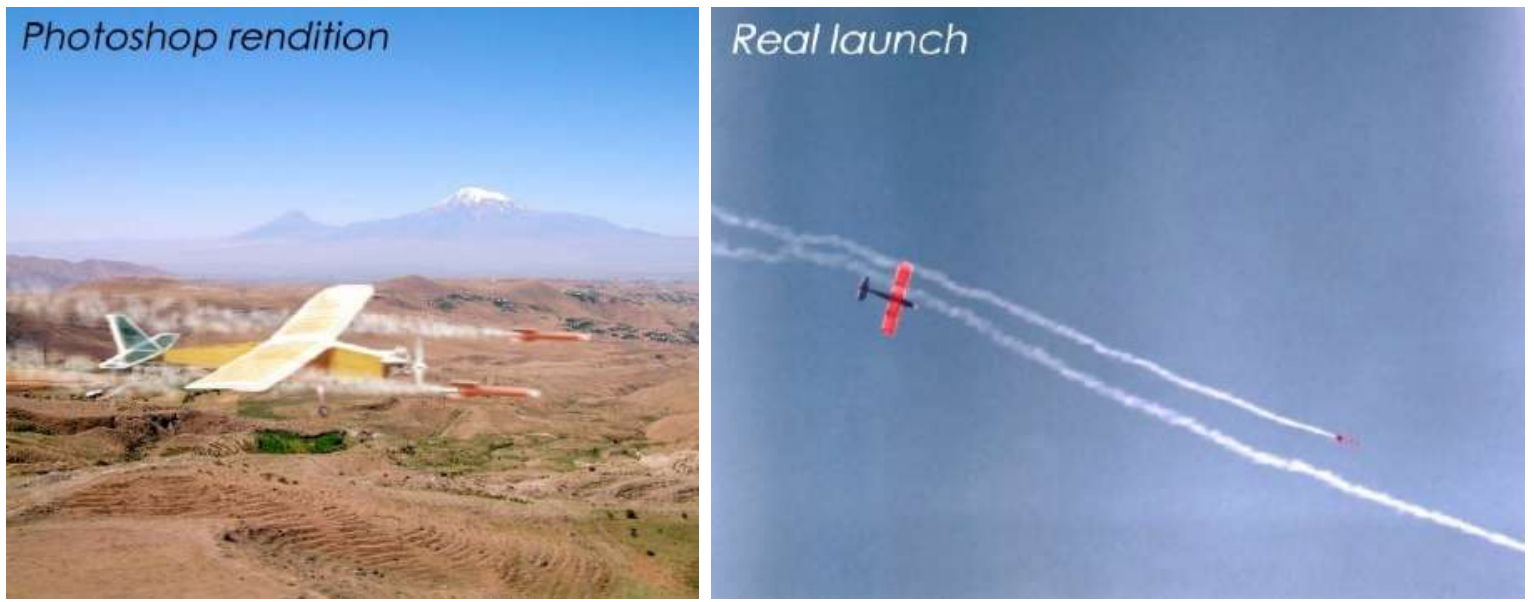

Figure 7. Air-to-ground missiles.

\section{Visiting Science and Technology Sites}

Over time, the visits to various science and technology sites became traditional (Figure 8): Byurakan Astrophysical Observatory, "Granit" Special Design Bureau, Aviation Institute, AREAL (Advanced Research Electron Accelerator Laboratory), CANDLE Synchrotron Research Institute, Herouni Radio-Optical telescope (ROT-54/2.6), Yerevan Aerology Station, airshows in Erebuni and Arzni airports, Museum of Space, planetarium, DigiTech Expo exhibitions, and so on. The students who managed to become a participant of an international contest got the opportunity to visit Zvyozdny Gorodok (the Star City) and Museum of Cosmonautics in Moscow, Special Astrophysical Observatory of the Russian Academy of Science in the Northern Caucasus (the telescopes BTA-6 and RATAN-600), Crimean Astrophysical Observatory, the Air and Space Museum near Paris, etc.

The most beloved site for the students is the Byurakan Astrophysical Observatory. They get acquainted with the observatory, its history and achievements, telescopes and ongoing activity, visit Viktor Ambartsumian's house-museum, observe the Sun and its spectrum, perform night observations, participate intellectual contests, launch model rockets, helicopters, balloons, gliders, kites, etc.
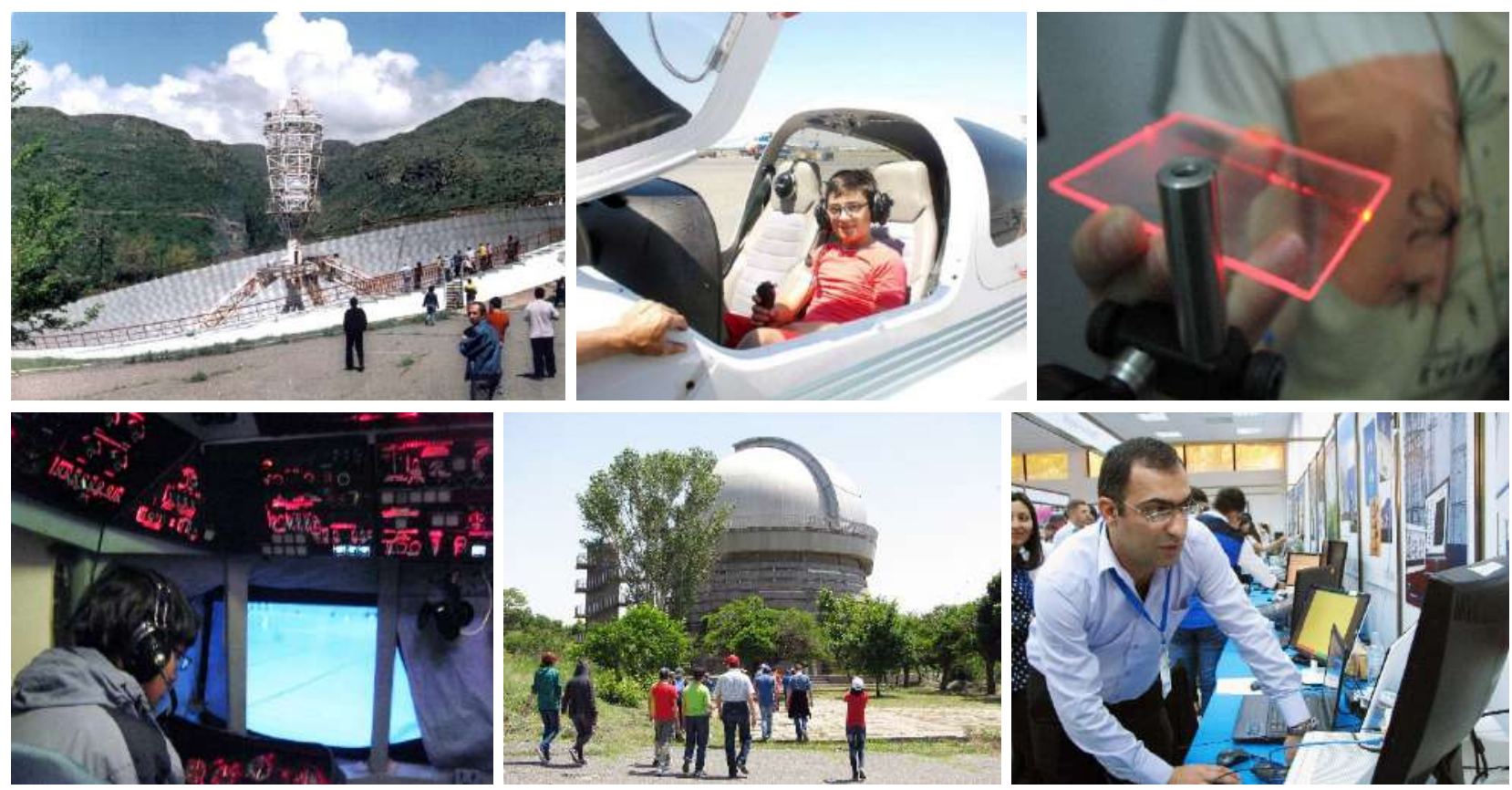

Figure 8. Visiting Science and Technology Sites. 


\section{Participation in International Olympiads}

In 1996 our two students for the first time participated the International Astronomy Olympiad (IAO), and Vazgen Ghazaryan ("AYAS" graduate and student of Yerevan Physic-mathematical school) was awarded a special diploma for the best result in the observational round. Next several years were missed because of the lack of funding. Only in 2000 the funding was provided and Tigran Shahverdyan ("AYAS" graduate and student of Yerevan Physic-mathematical school) won $2^{\text {nd }}$ degree diploma (silver medal) in IAO. Inspired by this success, in 2001 the Ministry of Science and Education of Armenia funded the participation of 6 people: 2 leaders (Avetik Grigoryan and Armen Oskanyan, who, by the way, took over the whole training work) and 4 students (Tigran Shahverdyan, Vahagn Yeghikyan, Mkrtich Soghomonyan, and Zhirayr Avetisyan). All of them were awarded $2^{\text {nd }}$ and $3^{\text {rd }}$ degree diplomas (bronze and silver medals). In 2002 Tigran Shahverdyan won also a bronze medal in the International Physics Olympiad (Figure 9)

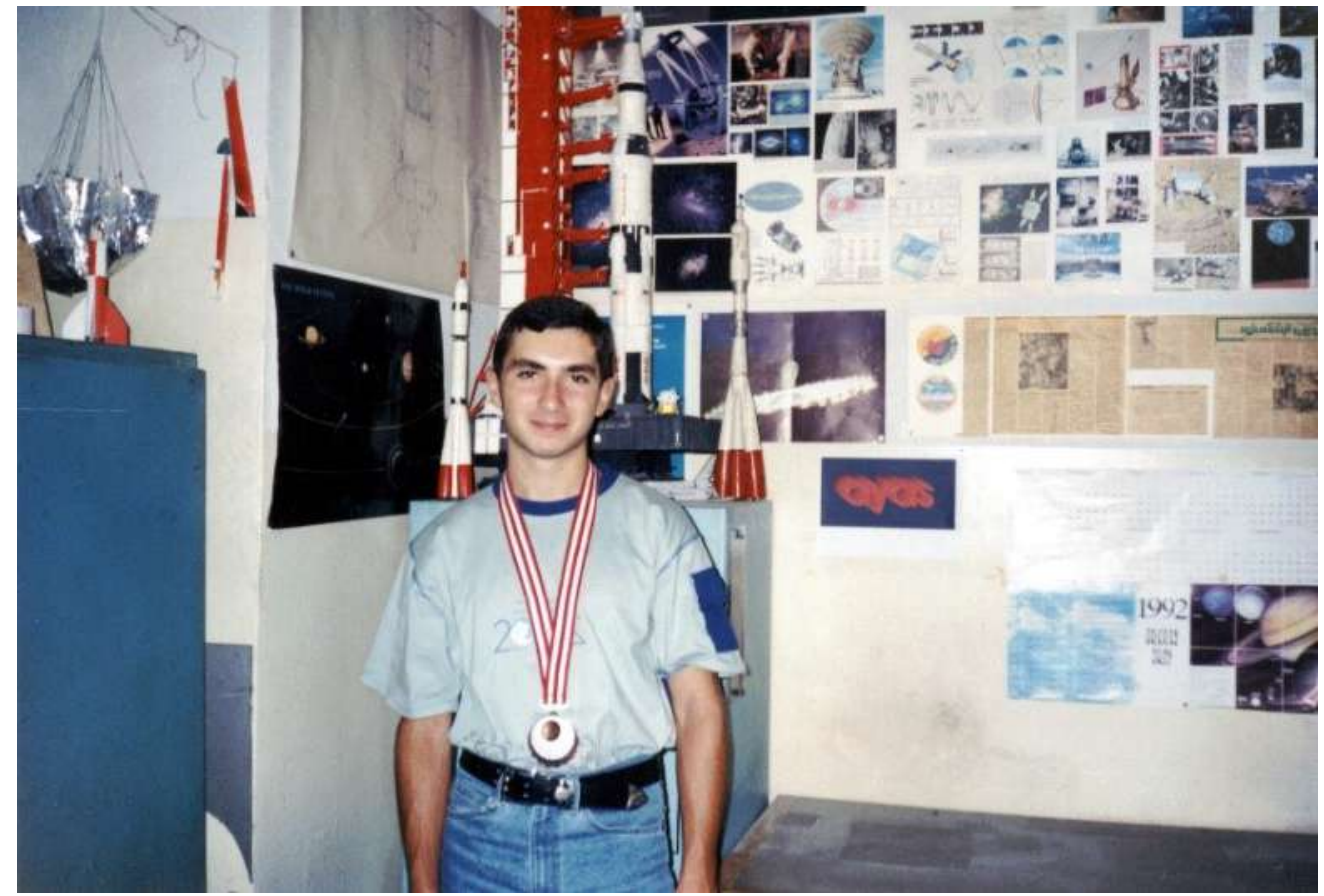

Figure 9. Tigran Shahverdyan

This was just the beginning of successful participation of our students in international Olympiads. Later, many of them (students of Quantum college and Yerevan Physic-mathematical school) won gold, silver and bronze medals in IAO, IOAA, IPhO, IOI, IBO, IZhO, etc.

\section{The Educational Course}

In 2002 our two-year educational course was already well developed and tested. The problem was that the wide range of topics (aeronautics, aviation, astronomy, and astronautics) and related subjects (physics, mathematics, chemistry, biology, technology) are strongly mutually interconnected with numerous links like in a tangled skein (Figure 10).

When explaining a certain topic, one needs to refer to other related subjects, then to others and so go all over around and find out that it is hard to avoid referring to notions that will be explained later. It was necessary to untangle this extremely tangled skein and sort the topics in the such an order that would allow to go all the time from simple notions to more complicated ones, from the learned material to the new ones and thus build the knowledge like a tower - from bottom to top. This was a rather complicated task given the wide range of topics. However, the solution was successfully found and it became the know-how of the developed course. 


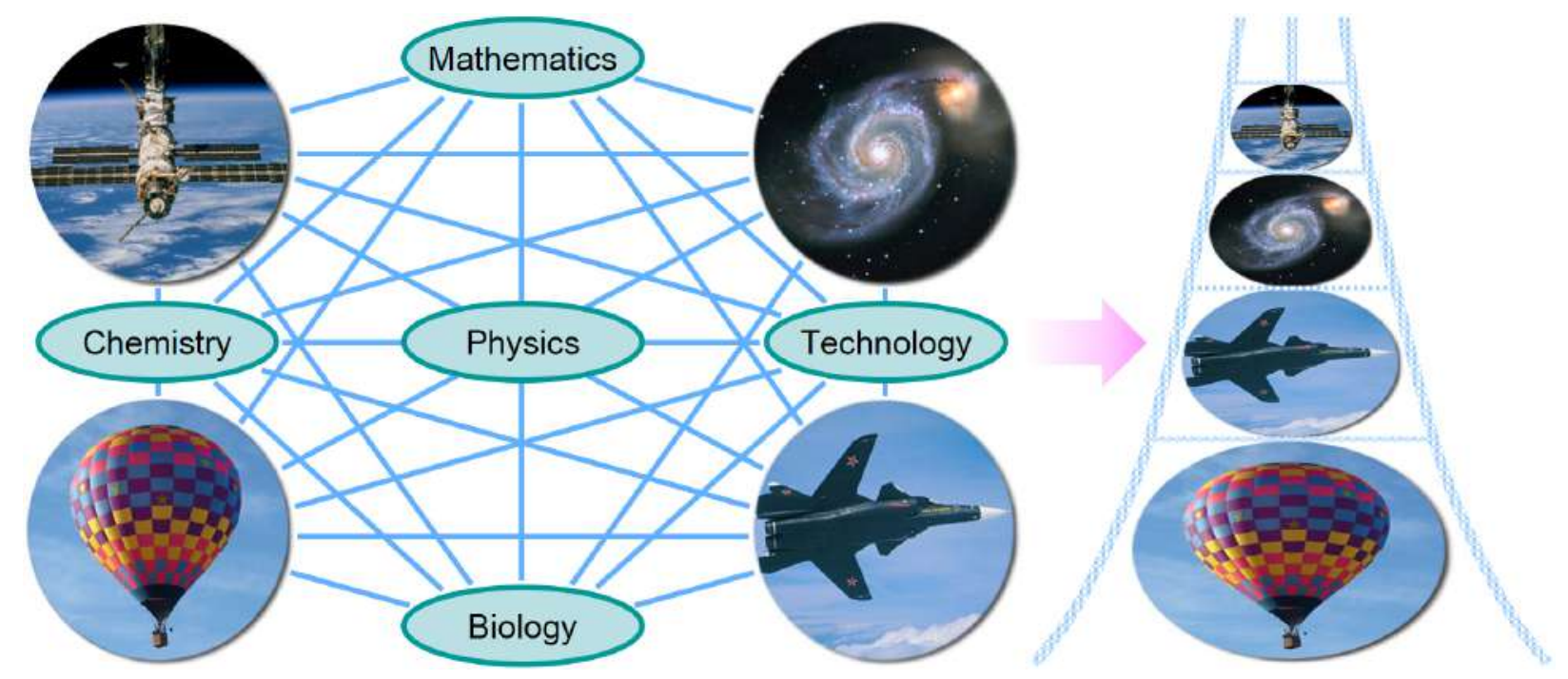

Figure 10. The know-how of the educational course.

\section{Popular Science Book}

Due to the developed educational course and the gained methodical experience a comprehensive popular science book "From the Deep of Ages to the Universe" was written in Armenian ${ }^{1}$ presenting a fascinating story about the path of cognition passed by the mankind in aeronautics, aviation, astronomy, and astronautics starting from the ancient ages to our time and the forthcoming space future (Figure 11). Under the attraction of the extraordinary phenomena and mysteries of outer space, this book leads the reader step by step from simplest and ordinary notions to deep understanding and encyclopedic knowledge in natural sciences and technology, awakes curiosity, develops ability and tendency to creative search and investigation, as well as gives a comprehensive view of the Universe and the history of its study.
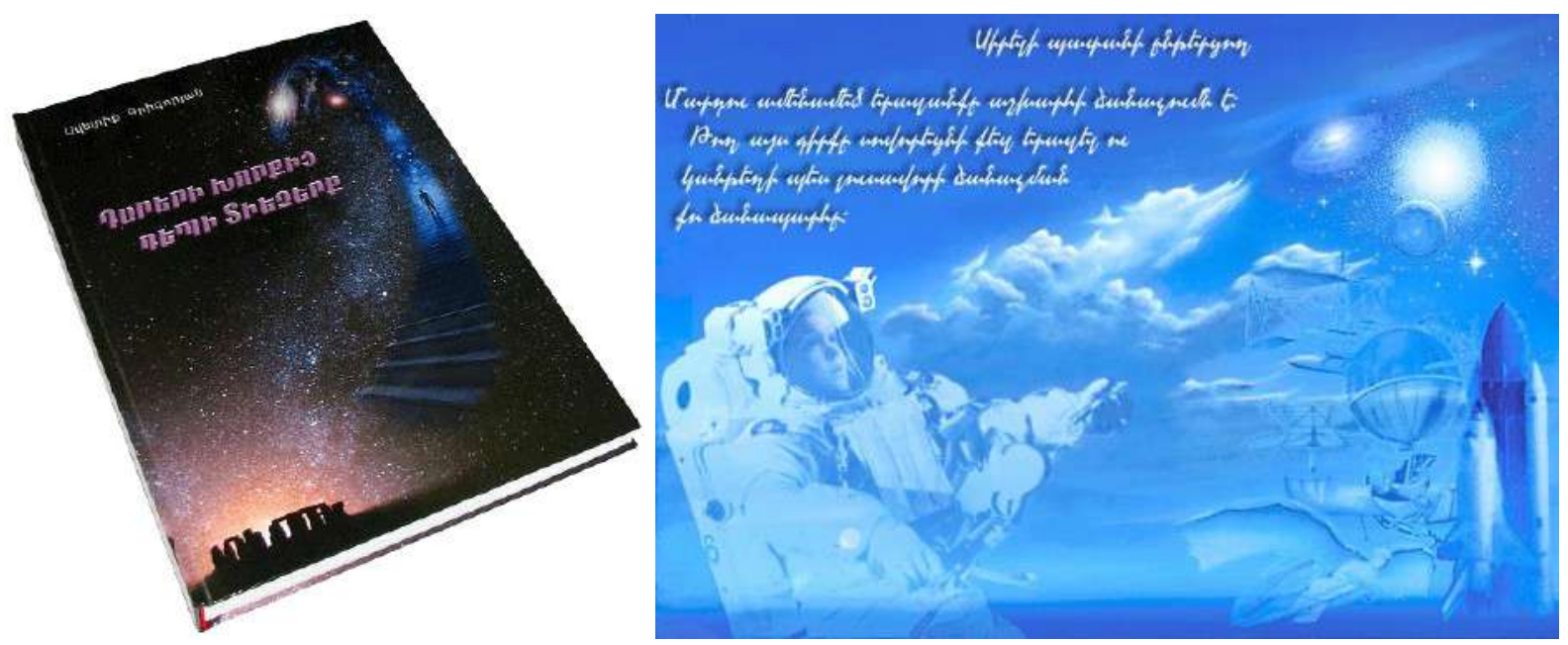

Figure 11. The book "From the Deep of Ages to the Universe".

This is not an encyclopedia of separate articles collected in one book. Such a style would not allow the reader to reach the required depth and get systematized knowledge and view, understand the relationship between different areas. Instead of that, the book is written in a systematic textbook sequence as a unified story of an adventurous journey through which the reader passes, gradually learning and understanding the world more and more deeply. This makes the reader read the book as a holistic novel, from the beginning up to the end, without jumping and skipping sections. The explanations are simple, intelligible and convincing.

\footnotetext{
${ }^{1}$ http: //books.ayaspace.info/en/about-the-book/
} 
The National Institute of Education of the Ministry of Science and Education of Armenia examined the book and recommended it as an auxiliary school-book for study of natural sciences in the secondary schools of Armenia.

The book was published in 2013, presented in National Academy ${ }^{2}$ and delivered to the school libraries of Armenia.

Due to the written content of the book, even before its publication, we easily transferred our educational course to colorful, obvious presentations full of explanatory pictures, photos, diagrams and animations making the course much more clear and efficient.

\section{8. "AYAS" Alumni}

Every generation of "AYAS" students loved attending the Club. It became their beloved educational hearth and a blissful place for them where they could satisfy their curiosity and find the answers to their numerous questions; gain serious scientific interests, comprehensive outlook and knowledge, ability to formulate scientific and technological problems; put forward innovative ideas; design, create, invent and discover.

They were happily working together in the Club, supporting each other as they could, making incredible leaps of creative thought and enjoying together their success. Sometimes after classes, it was hard to convince them to go home.

Later, they realize how important was their involvement in "AYAS" activity, how it changed their life, making it much more interesting and successful. So, one of the memorable events in their life is getting the graduation diploma from "AYAS" (Figure 12).
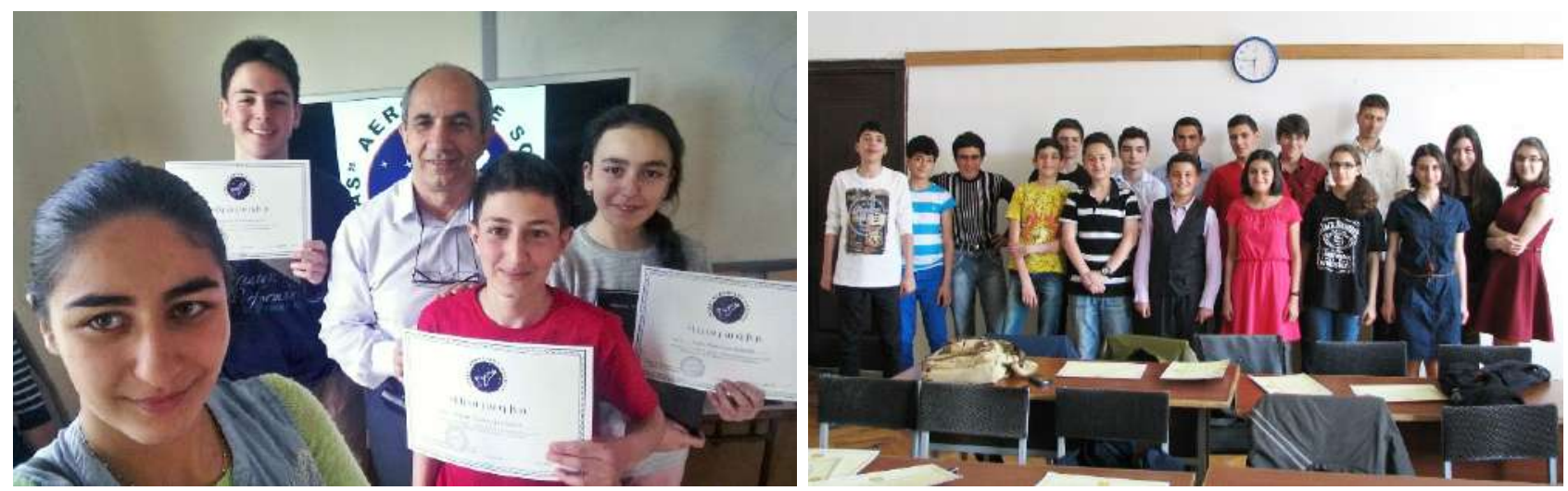

Figure 12. Graduation.

Many of them became close friends and after graduating the training course kept their relationships with the Club and its members, supported the Club's activity with all their skills and abilities never waiting for others to do that. So today's sponsors of the Club are first of all its members and alumni.

The "AYAS" members made impressive success in their career. They had significant achievements in studying natural sciences (many diplomas from international Olympiads and competitions) and after graduation became highly qualified specialists: physicists, astronomers, mathematicians, programmers, and engineers. Many of them are working now in Armenia and some in the USA, Europe, and Russia (14 Doctors of Philosophy, and one Doctor of Science, professor). Among the graduates of the training course - 10 medalists of International Olympiads (Olympiads of astronomy, physics, biology, mathematics and informatics), six winners of annual educational award of Armenia's president, two laureates of Presidential Award and two laureates of State Award in natural sciences. They also contribute to education in Armenia by teaching in different educational centers (Figure 13).

\footnotetext{
${ }^{2}$ https : / / www . youtube.com/watch?v=stdvuzJJSZw\&f eature=youtu . be
} 


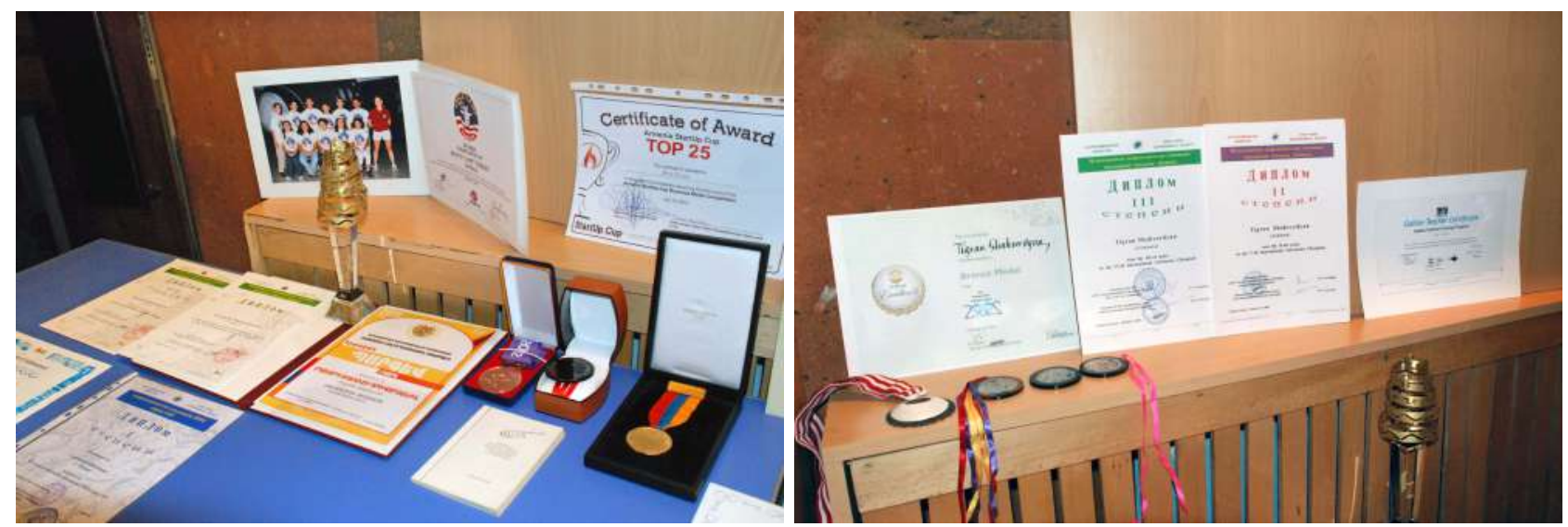

Figure 13. International awards and diplomas.

\section{Events}

Besides visiting science and technology sites, we have arranged a lot of events inviting for participation not only "AYAS" members but also everybody interested in the event: seminars on different topics, meetings with specialists in aerospace-related areas (pilots, cosmonauts, astronauts) (Figure 14), forums and celebrations.

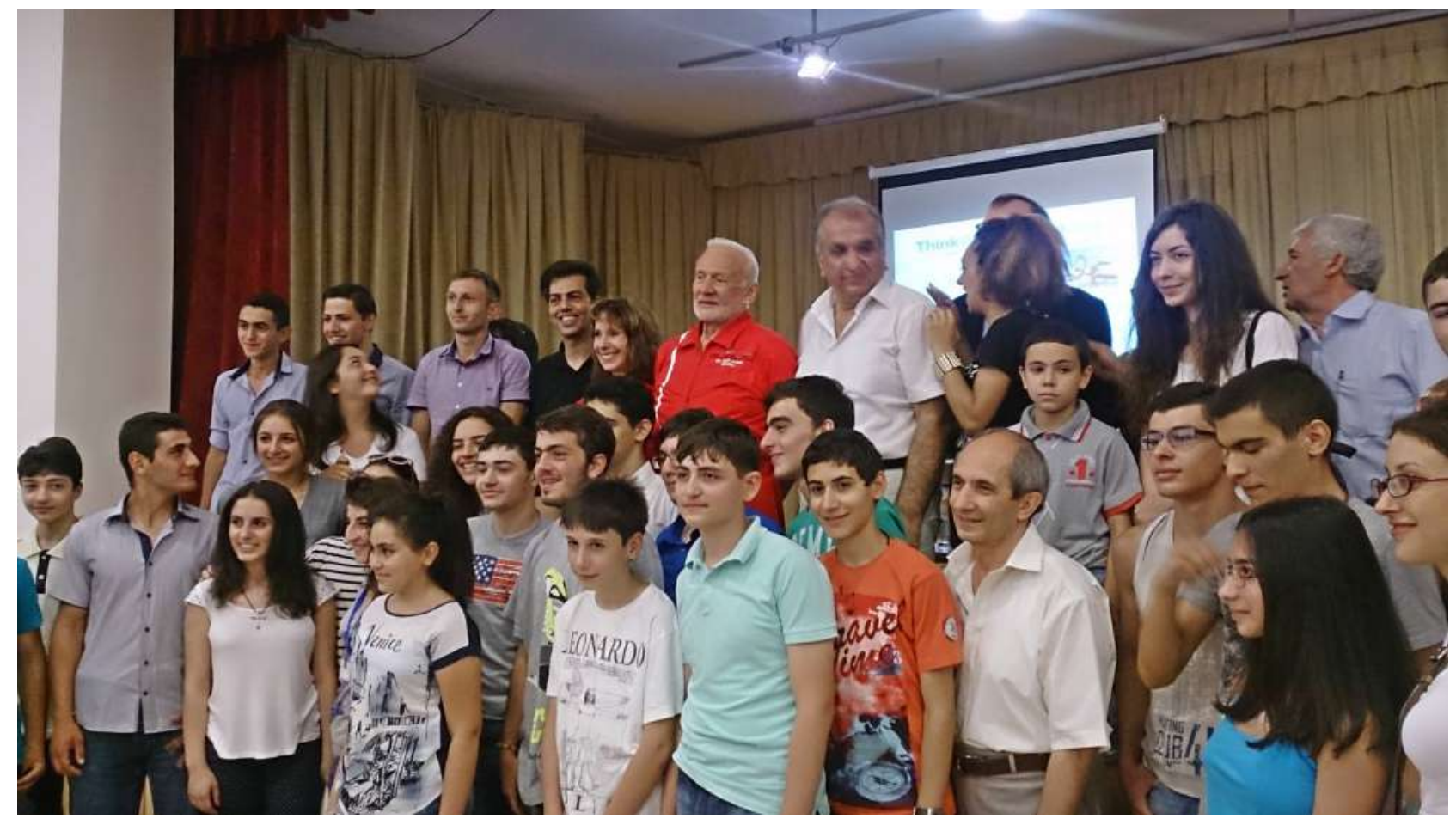

Figure 14. Meeting with Buzz Aldrin.

For the senior members of "AYAS", one of the ways of supporting the Club's activity was delivering seminar lectures on the topics of their professional areas. This was extremely useful for the juniors to get acquainted with the front end areas and problems of modern science and technologies (Figure 15). The example of seniors inspires the juniors and shows that they also can work hard and achieve such success.

In order to link the generations of "AYAS" members of different years, we tried to involve them together in our events and even arranged special forums for introducing them to each other, encouraged to exchange contacts and ideas, support each other in their career and even work together (Figure 16). 

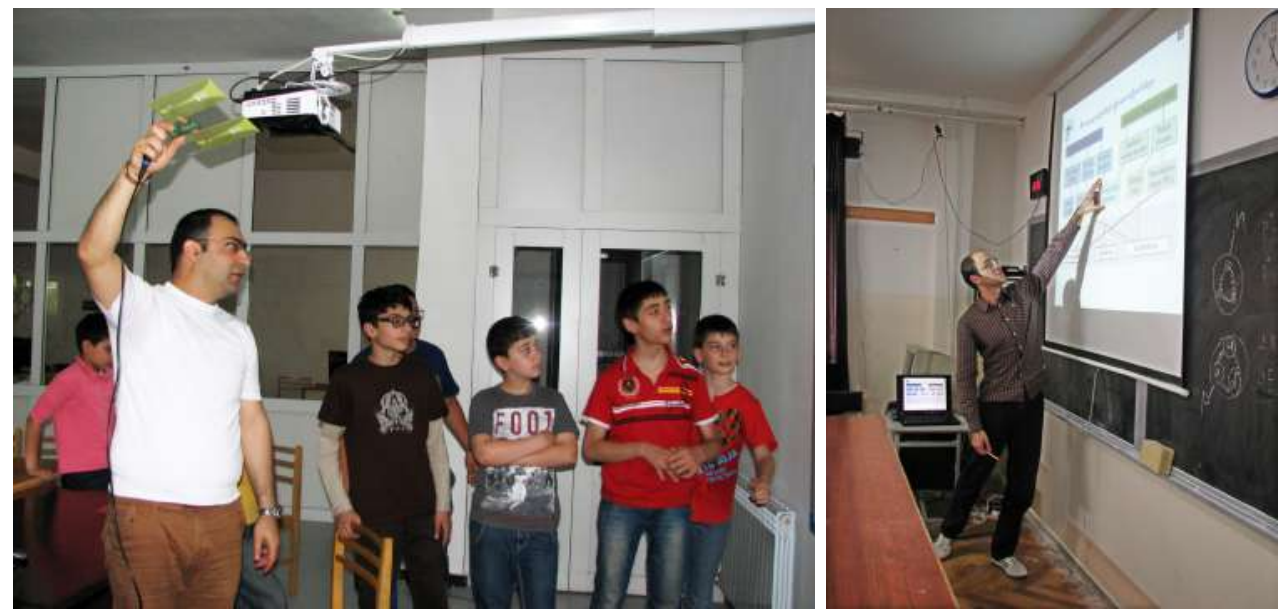

Figure 15. Seniors teaching juniors.
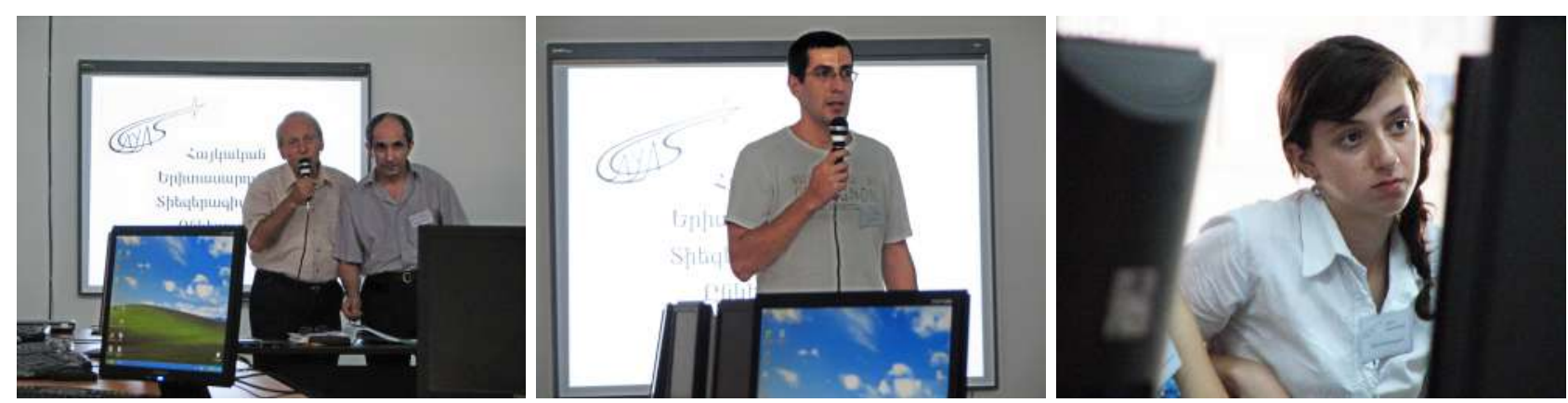

Figure 16. All-"AYAS" forum.

In 2013 we celebrated the $25^{\text {th }}$ anniversary of "AYAS" (Figure 17), reviewed our history and outlined the future goals and plans ${ }^{3}$. The contribution of each of us, as well as partners, associates and supporters (students, scientists, educators, directors of Schools and Scientific institutions, journalists) was mentioned and appreciated. The "AYAS" members were awarded special certificates of honor on the occasion of the $25^{\text {th }}$ anniversary of "AYAS".
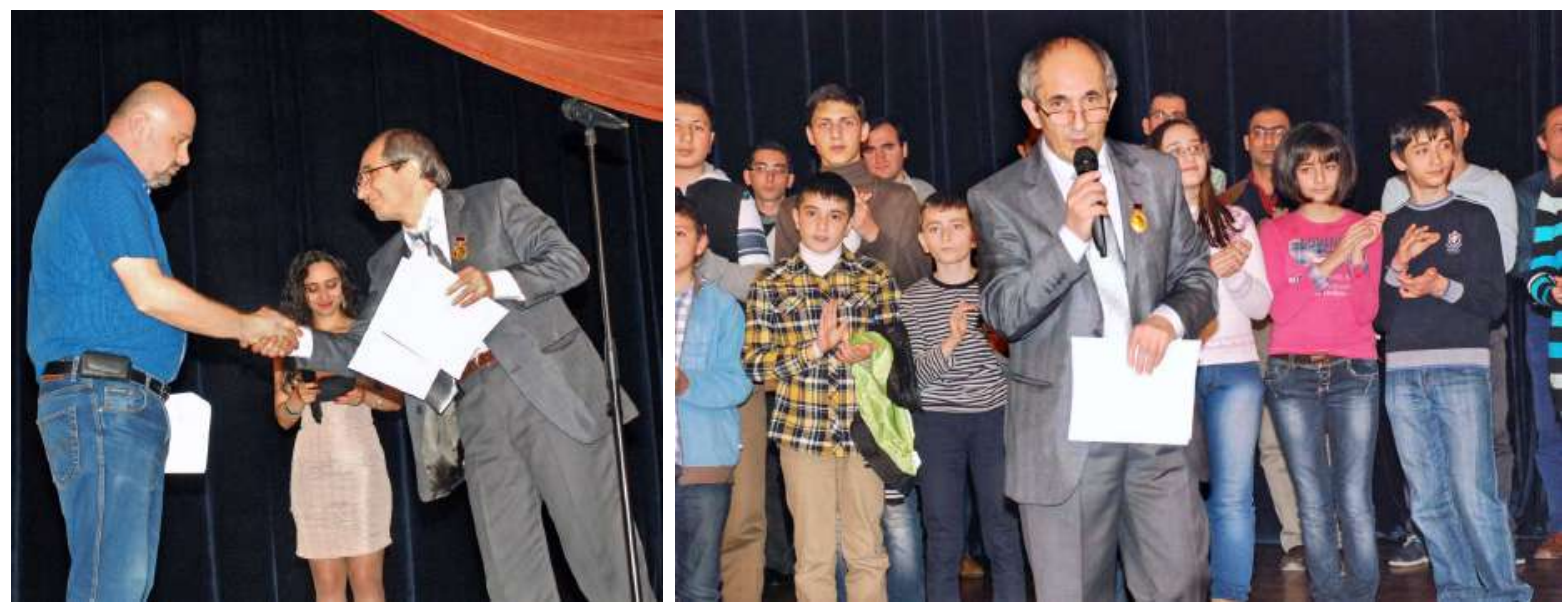

Figure 17. Celebration of "AYAS" $25^{\text {th }}$ anniversary.

\footnotetext{
${ }^{3}$ https: //www . youtube. com/watch?v=4oMMV1C0yCg
} 


\section{Foundation of "AYAS" Aerospace Society}

From the very beginning of our activity, it was obvious that we are actually performing as an active non-governmental organization, not just a study group or club. We tried to officially fix this status but realized that it will not make any sense to struggle the bureaucratic obstacles and achieve that goal when we have no sponsors, no chance for financial support, not even sufficient level, experience and resources for initiating serious scientific and engineering research projects and applying for international grants.

However, in 2018 the situation started to radically change. The elder generation of "AYAS" graduates has grown up and could already provide its expertise. The opportunities for getting involved in international projects, participating in different local and international inducement prize competitions, participating governmental initiatives as a legal entity also grew. We even gained experience of founding "AYAS" clubs in other educational centers of Armenia (two schools in Yerevan and the COAF SMART Center in the Lori province) in parallel with the main Club operating in the Quantum college (Figure 18). Thus, our activity started spreading throughout Armenia and involving not only students but everybody interested in aerospace-related areas and rooting for "AYAS".
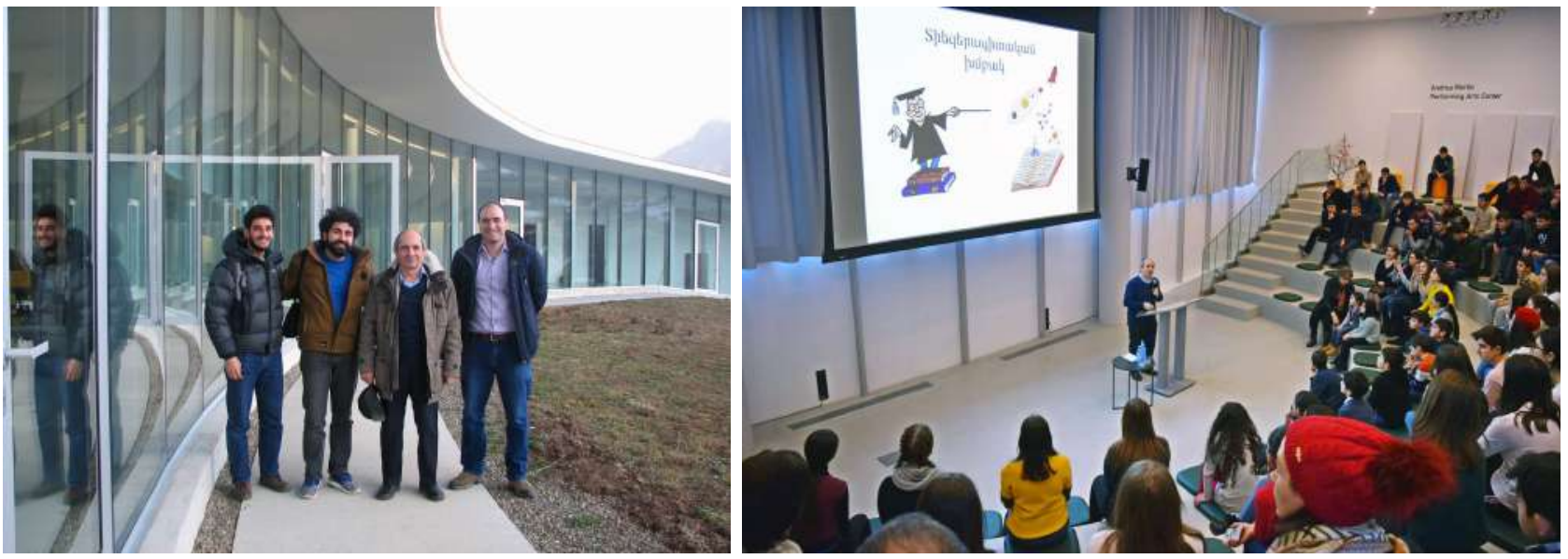

Figure 18. Opening "AYAS" club in the COAF SMART Center.

So, it was high time to officially register our organization with its statute (Figure 19), logo, and certified seal. In May 2018 the "AYAS" Aerospace Club was certified as "AYAS" Aerospace Society".

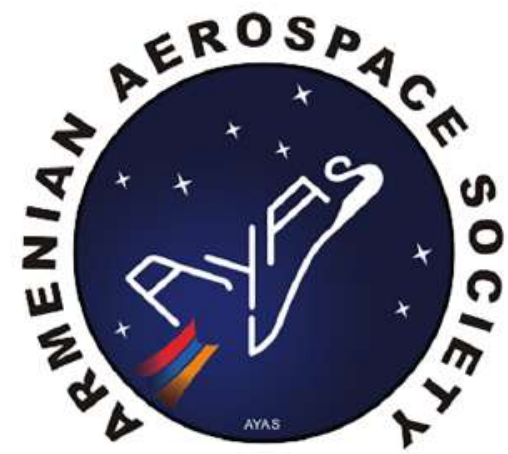

Figure 19. "AYAS" logo.

\section{Future Goals and Plans}

The official registration as an NGO imposed new tasks and responsibilities requiring us to intensify our activity and work on a higher level. The following goals for "AYAS" are now targeted for the

\footnotetext{
${ }^{4}$ https://www.facebook.com/ayasspace/
} 
upcoming 5 years:

- Develop new educational project "Science in School" for spreading the experience and culture of conducting research works in school gained by "AYAS" and Quantum college over other schools of Armenia. Discuss this initiative with the Ministry of Education, Science, Culture and Sports of Armenia, promote its conceptual and procedural ideas for including them in the concepts of the upcoming republican competitions of school student's research works.

- Intensify the research activity of "AYAS" so that it will require a higher scientific-technological level.

- Establish collaboration with the universities of Armenia, first of all with the Yerevan State University, American University of Armenia, State Engineering University of Armenia, and Russian-Armenian University, involve their students in "AYAS" activity, assist and encourage them to create their own research groups.

- Establish collaboration with Space Remote Sensing companies of different countries, obtain corresponding educational and technical resources for this activity and involve the university and school students of Armenia in analyzing the space images of Earth and Mars.

- Establish a new field of "AYAS" activity - high altitude balloons and platforms, develop and accomplish corresponding projects.

- Using all possible means promote Armenia towards establishing its National Space Agency, developing its National Space Program and starting activity in space to become a space-faring country. "AYAS" should have significant contribution in designing and creating the CubeSat that will be launched as the first Armenian satellite. 